\title{
INVESTIGATION OF ACCURACY OF THE INTERFACE TRACKING METHOD
}

\author{
Ewa Węgrzyn-Skrzypczak ${ }^{1}$, Tomasz Skrzypczak ${ }^{2}$ \\ ${ }^{1}$ Institute of Mathematics, Czestochowa University of Technology \\ Czestochowa, Poland \\ ${ }^{2}$ Institute of Mechanics and Machine Design, Czestochowa University of Technology \\ Czestochowa, Poland \\ ${ }^{1}$ ewa.skrzypczak@im.pcz.pl, ${ }^{2}$ skrzyp@imipkm.pcz.pl
}

\begin{abstract}
In this paper accuracy of a simple and effective method for tracking interfaces in two-dimensional area is investigated. The method is based on the level set method (LSM) with "brute force" reinitialization algorithm. A comparison of numerical solution with an analytical solution is presented and discussed.
\end{abstract}

Keywords: level set method, interface tracking, area loss

\section{Introduction}

One of the most popular numerical techniques for tracking internal boundaries developed in the recent years is LSM. This method can perform numerical computations on a fixed grid. Also, LSM makes it very easy to follow internal interfaces when they split, merge, develop holes, etc. It is very useful in two- and three-dimensional cases. A level set method was developed by J.A. Sethian and S. Osher in the 1980s [1] and extensively used for the next years [2-7]. LSM is a powerful and widely-used method for the propagation of internal interfaces during solidification of pure metals $[8,9]$ and alloys in the micro-scale, two-phase flows, cracks propagation, computer vision, images processing, etc.

One of the main challenges facing the researchers during years was to study the accuracy of numerical solutions based on the LSM. The method can provide results of varying accuracy depending on the accuracy of the spatial discretization of the area or volume. Additionally, reinitialization procedure introduces an extra error often called "the area loss" $[10,11]$.

\section{Governing equation}

Hyperbolic first order differential equation governs the movement of internal boundary 


$$
u_{n}|\nabla \varphi|=-\frac{\partial \varphi}{\partial t}
$$

where $u_{n}\left[\mathrm{~m} \mathrm{~s}^{-1}\right]$ is the velocity of the interface in the normal direction computed according to the equation shown below

$$
u_{n}=\mathbf{n}^{s} \cdot \mathbf{u}=\frac{\nabla \varphi}{|\nabla \varphi|} \cdot \mathbf{u}
$$

Equation (1) describes the so-called initial problem. In the case of such problems only initial condition must be defined. The distance function $\varphi$ i.e. position of the interface at $t=0 \mathrm{~s}$ must be known.

\section{Examples of calculation}

Test calculations were performed for the simple case of internal interfaces moving at a constant speed. In each test, the temporary positions of the interface were calculated analytically and then compared with the positions which were calculated numerically.

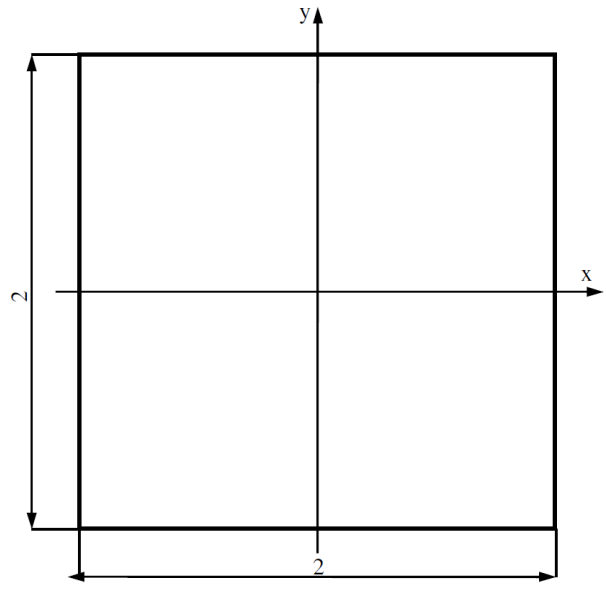

Fig. 1. Test area (dimensions in meters)

The test area was a square of $2 \times 2 \mathrm{~m}$ (Fig. 1). It was subjected to a spatial discretization using triangular finite elements. The number of nodes in the direction of horizontal and vertical axis was 201, corresponding to a total of 40401 nodes in the whole mesh.

The first test concerned the movement of the interface forming a straight line at a constant speed of $v=0.01 \mathrm{~m} \mathrm{~s}^{-1}$. The initial position of the internal boundary has been fixed for $x_{0}=-1$. The direction of movement was determined along the horizontal axis. Exact position of the interface was calculated with the use of following equation 


$$
X(t)=x_{0}+v t
$$

Figure 2 shows temporary positions of the interface calculated numerically and analytically. The differences between them are negligible. The area over which the interface was moving is calculated. The percentage of the area to the entire region is calculated. The exact and numerical results are summarized in Table 1. The differences do not exceed $0.25 \%$.

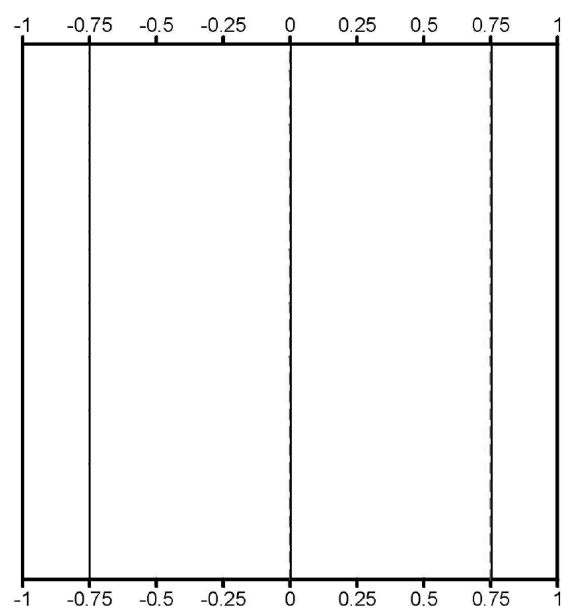

Fig. 2. The position of the interface at $25,100,175 \mathrm{~s}$ after the start

Table 1

Percentage share of the area on the left side of the interface

\begin{tabular}{|c|c|c|}
\hline $\begin{array}{c}\text { Time } \\
{[\mathrm{s}]}\end{array}$ & $\begin{array}{c}\text { Exact results } \\
{[\%]}\end{array}$ & $\begin{array}{c}\text { Numerical results } \\
{[\%]}\end{array}$ \\
\hline 25 & 12.5 & 12.6 \\
\hline 100 & 50.0 & 50.17 \\
\hline 175 & 87.5 & 87.73 \\
\hline
\end{tabular}

A second test concerned the expansion of the circular interface with an initial radius of $r_{0}=0.01 \mathrm{~m}$ at a constant speed of $v=0.01 \mathrm{~m} \mathrm{~s}^{-1}$. Exact length of the radius was calculated according to the following formula

$$
R(t)=r_{0}+v t
$$

Temporary positions of the interface are presented in Figure 3. Small deformation of the shape is observed. Calculated temporary positions of the zero level isolines are not perfect circles. Table 2 shows the percentages of the areas surrounded by the interface. The differences obtained by comparing the positions calculated analytically and numerically do not exceed $2.5 \%$. 
Percentage share of the area inside the interface

\begin{tabular}{|c|c|c|}
\hline $\begin{array}{c}\text { Time } \\
{[\mathrm{s}]}\end{array}$ & $\begin{array}{c}\text { Exact results } \\
{[\%]}\end{array}$ & $\begin{array}{c}\text { Numerical results } \\
{[\%]}\end{array}$ \\
\hline 0 & 0.7817 & 0.7817 \\
\hline 15 & 4.902 & 4.688 \\
\hline 40 & 19.615 & 18.865 \\
\hline 65 & 44.175 & 42.718 \\
\hline 90 & 78.54 & 76.202 \\
\hline
\end{tabular}

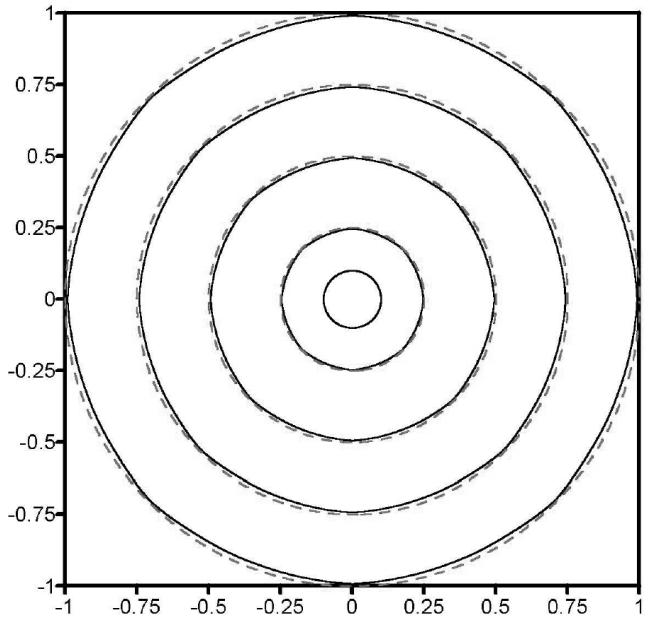

Fig. 3. The position of the interface at $0,15,40,65,90 \mathrm{~s}$ after the start

The last test concerned the expansion of the two interfaces in the shape of circles arranged symmetrically with respect to the y-axis, with initial radii of $r_{1}=r_{2}=0.01 \mathrm{~m}$ at constant velocities $v_{1}=v_{2}=0.01 \mathrm{~m} \mathrm{~s}^{-1}$. Exact length of each radius was calculated according to the formulas shown below

$$
R_{1}(t)=r_{1}+v_{1} t, \quad R_{2}(t)=r_{2}+v_{2} t
$$

Temporary positions of the interfaces are presented in Figure 4. The differences between the positions calculated analytically and numerically are acceptable and even less than that of the second test. Table 3 summarizes the test results.

The differences between calculated values resulting from the error of the adopted numerical method are less or equal to $1.7 \%$. 


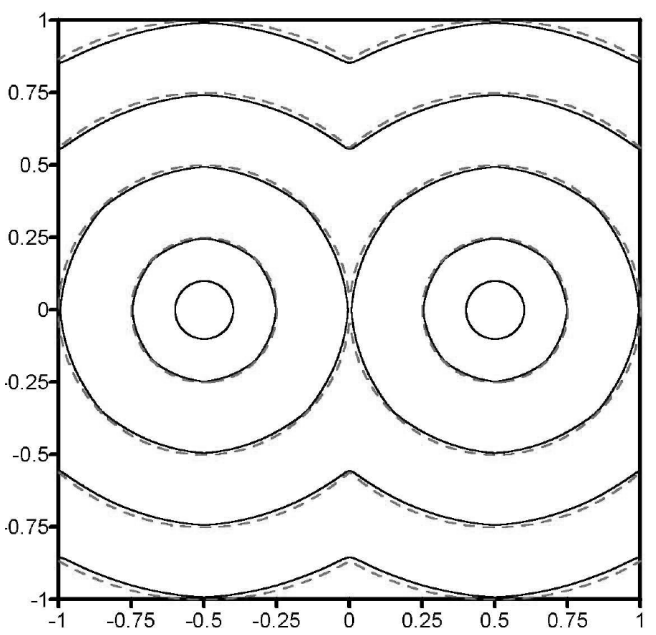

Fig. 4 . The position of the interface at $0,15,40,65,90 \mathrm{~s}$ after the start

Table 3

Percentage share of the area inside the jointed interfaces

\begin{tabular}{|c|c|c|}
\hline $\begin{array}{c}\text { Time } \\
{[\mathrm{s}]}\end{array}$ & $\begin{array}{c}\text { Exact results } \\
{[\%]}\end{array}$ & $\begin{array}{c}\text { Numerical results } \\
{[\%]}\end{array}$ \\
\hline 0 & 0.7817 & 0.7817 \\
\hline 15 & 4.902 & 4.688 \\
\hline 40 & 19.615 & 18.865 \\
\hline 65 & 44.175 & 42.718 \\
\hline 90 & 78.54 & 76.202 \\
\hline
\end{tabular}

\section{Conclusions}

On the basis of the results obtained during the tests it was found that the errors in the numerical solutions are of acceptable degree thus the method of tracking internal boundaries is effective.

\section{References}

[1] Osher S., Sethian J.A., Fronts propagating with curvature-dependent speed: Algorithms based on Hamilton-Jacobi formulations, Journal of Computational Physics 1988, 79, 12-49.

[2] Adalsteinsson D., Sethian J.A., A fast level set method for propagating interfaces, Journal of Computational Physics 1995, 118, 269-277.

[3] Barth T., Sethian J., Numerical schemes for the Hamilton-Jacobi and level set equations on triangulated domains, Journal of Computational Physics 1998, 145, 1-40.

[4] Sethian J.A., Fast marching methods, SIAM Review 1999, 41, 199-235. 
[5] Sethian J.A., Curvature and the evolution of fronts, Communications in Mathematical Physics 1985, 101, 487-499.

[6] Sethian J.A., Numerical methods for propagating fronts, [in:] Variational Methods for Free Surface Interfaces, New York 1987, 155-164.

[7] Sethian J.A., Fast marching methods and level set methods for propagating interfaces, [in:] von Karman Institute Lecture Series, Computational Fluid Mechanics 1998.

[8] Skrzypczak T., Węgrzyn-Skrzypczak E., Mathematical and numerical model of solidification process of pure metals, International Journal of Heat and Mass Transfer 2012, 55(15-16), 4276-4284 .

[9] Skrzypczak T., Sharp interface numerical modeling of solidification process of pure metal, Archives of Metallurgy and Materials 2012, 57(4), 1189-1199.

[10] Peng D., Merriman B., Osher S., Zhao H., A PDE-based fast local level set method, Journal of Computational Physics 1999, 155, 410-438.

[11] Sussman M., Fatemi E., An efficient interface preserving level set re-distancing algorithm and its applications to interfacial incompressible fluid flow, Journal of Scientific Computing 1999, 20, 1165-1191. 